\title{
Effects of maternal and paternal smoking on attentional control in children with and without ADHD
}

\author{
Marieke E. Altink · Dorine I. E. Slaats-Willemse - Nanda N. J. Rommelse • \\ Cathelijne J. M. Buschgens · Ellen A. Fliers · Alejandro Arias-Vásquez $\cdot$ Xiaohui Xu • \\ Barbara Franke $\cdot$ Joseph A. Sergeant $\cdot$ Stephen V. Faraone $\cdot$ Jan K. Buitelaar
}

Received: 20 August 2008/ Accepted: 19 January 2009/Published online: 14 March 2009

(C) The Author(s) 2009. This article is published with open access at Springerlink.com

\begin{abstract}
Maternal smoking during pregnancy is a risk factor for attention-deficit/hyperactivity disorder (ADHD), but data on its adverse effects on cognitive functioning are sparse and inconsistent. Since the effect of maternal smoking during pregnancy may be due to correlated genetic risk factors rather than being a pure environmental effect, we examined the effect of prenatal exposure to smoking on attentional control, taking into account the
\end{abstract}

M. E. Altink · D. I. E. Slaats-Willemse ·

C. J. M. Buschgens · E. A. Fliers · A. Arias-Vásquez •

B. Franke · J. K. Buitelaar $(\bowtie)$

Department of Psychiatry, Donders Centre for Neuroscience, Radboud University Nijmegen Medical Centre, P.O. Box 9101, HP 966, 6500 HB Nijmegen, The Netherlands

e-mail: j.buitelaar@psy.umcn.nl

M. E. Altink - D. I. E. Slaats-Willemse - J. K. Buitelaar Karakter Child and Adolescent University Centre Nijmegen, Reinier Postlaan 12, 6525 GC Nijmegen, The Netherlands

N. N. J. Rommelse · J. A. Sergeant

Department of Clinical Neuropsychology, VU University Amsterdam, Van der Boechorststraat 1, 1081 BT Amsterdam, The Netherlands

A. Arias-Vásquez · B. Franke

Department of Human Genetics, Radboud University Nijmegen Medical Centre, HP 855, P.O. Box 9101, 6500 HB Nijmegen,

The Netherlands

X. Xu

MRC Social Genetic Developmental and Psychiatry Centre, Institute of Psychiatry, King's College London, De Crespigny Park, London SE5 8AF, UK

S. V. Faraone

Departments of Psychiatry and Neuroscience \& Physiology, SUNY Upstate Medical University, Weiskotten Hall 3285, Syracuse, NY 13210, USA effects of both maternal and paternal smoking, and examined whether these effects were genetically mediated by parental genotypes. We further examined whether the effect of prenatal exposure to smoking on attentional control interacted with genotypes of the child. Participants were 79 children with ADHD, ascertained for the International Multi-centre ADHD Gene project (IMAGE), and 105 normal controls. Attentional control was assessed by a visual continuous performance task. Three genetic risk factors for ADHD (DRD4 7-repeat allele of the exon 3 variable number of tandem repeats (VNTR), DAT1 10/10 genotype of the VNTR located in the $3^{\prime}$ untranslated region, and the DAT1 6/6 genotype of the intron 8 VNTR) were included in the analyses. Paternal smoking had a negative effect on attentional control in children with ADHD and this effect appeared to be mediated by genetic risk factors. The prenatal smoking effect did not interact with genotypes of the child. Maternal smoking had no main effect on attentional control, which may be due to lower smoking rates. This study suggests that the effects of paternal smoking on attentional control in children with ADHD should be considered a proxy for ADHD and/or smoking risk genes. Future studies should examine if the results can be generalized to other cognitive domains.

Keywords ADHD - Genetics - Smoking - Pregnancy . Response time variability

\section{Introduction}

Attention deficit hyperactivity disorder (ADHD) [1] is a neurodevelopmental disorder with onset early in life. Its pervasive pattern of inattentive, impulsive and/or hyperactive behaviors leads to impairment of functioning in 
important areas such as family life, school and peer interaction. ADHD is a rather common disorder with a pooled prevalence of $5.3 \%$ worldwide [41]. ADHD extends well beyond the core clinical symptoms, and may include deficits in various cognitive functions [49]. An important cognitive deficit is poor attentional control, as shown by larger variability in reaction times in children with ADHD in contrast to normal controls [19, 47, 50]. Attentional control is the central cognitive ability needed to maintain a stable performance over a prolonged period of time and is considered as an important parameter in evaluating sustained attention deficits. Attentional control has been proposed as a possible endophenotype, i.e., a latent trait that forms a link between the genotype and phenotype of ADHD, and is therefore promising for use in genetic research [8].

Although considerable progress has been made to unravel the etiology of ADHD, its precise causes remain unclear. Different lines of evidence from twin, adoption and molecular genetic studies clearly support an important role for genetic factors in disease etiology [17, 31]. Currently, ADHD is best conceptualized as a complex disorder in which multiple genetic factors, each of small effect size, interact with each other as well as with environmental factors [7]. Among the environmental factors found to be relevant for the development of ADHD are, in particular, pregnancy and delivery complications, low birth weight, and exposure to toxins in utero [3]. Most but not all casecontrol and cohort studies found maternal prenatal smoking to lead to a 2- to 4-fold increased risk for ADHD [28, 32]. Environmental risk factors such as prenatal exposure to smoking may be particularly harmful in combination with disease susceptibility genes through gene-environment $(\mathrm{G} \times \mathrm{E})$ interactions [38].

Prenatal exposure to smoking has also been shown to affect various aspects of cognitive functioning. Prenatal cigarette exposure has been associated with an on average 2.9 points lower IQ, with problems in inhibition, eye-hand coordination, memory and problem solving [9, 23], lower academic performance [4] and lower attention scores assessed by the continuous performance test in 10-yearolds [30], even after controlling for socio-economic status, parental IQ and parental ADHD status [5, 33, 35]. These cognitive deficits resulting from prenatal cigarette exposure may persist into young adulthood [15]. However, data on the adverse effects of prenatal exposure to smoking on the cognitive functioning of children are sparse and less consistent than those on behavioral outcomes [39]. Moreover, few data are available on the effect of prenatal exposure to smoking on attentional control in children with ADHD and its potential interaction with genetic risk factors in the child.

Investigating the effect of smoking during pregnancy on ADHD is complicated by gene-environment correlation.
Adults with ADHD smoke significantly more often than adults without ADHD [26], and smoking appears to be familial among ADHD families, but not among control families [36]. A Finnish study notes paternal smoking history to be as strongly related to increased risk for ADHD and aggression as maternal smoking during pregnancy [16]. Furthermore, genes involved in dopamine function or nicotinic receptor activity have been found associated with both ADHD and smoking addiction. An association was found between the ADHD risk allele of the exon 3 variable number of tandem repeats (VNTR) in the dopamine D4 receptor gene (DRD4) and smoking in males, but not in females [29]. Conversely, it has been suggested that the nicotinic acetylcholine receptors are also involved in ADHD and related cognitive deficits (e.g., sustained attention), because of their (mediating) role in dopamine neurotransmission [42]. In sum, there seems to be a shared genetic predisposition for smoking and ADHD. Recent twin studies indicate that the effect of prenatal exposure to maternal smoking on symptoms of ADHD and conduct disorder in offspring decreases substantially, when genetic factors are controlled for [25, 34, 54]. Thus, the effect of maternal smoking during pregnancy on cognitive functioning in the child could be due to the transmission of genetic risk factors rather than being a pure environmental effect. If so, paternal smoking would be predicted to have at least similar effects on cognitive functioning as maternal smoking.

In sum, the main aim of this study is to examine the effect of prenatal exposure to maternal and paternal smoking on attentional control in children with ADHD and control children, and examine whether these effects are genetically mediated by parental genotypes. An additional aim is to explore whether the effect of prenatal exposure to smoking on attentional control interacts with genotypes of the child. We will include three known genetic risk factors for ADHD [6], i.e., the DRD4 exon 3 VNTR 7-repeat allele, the dopamine transporter (DATl) 10/10 genotype of the VNTR located in the $3^{\prime}$ untranslated region (UTR) and the DATl $6 / 6$ genotype of the VNTR intron 8 VNTR (INT8), and control for possible covariates, like ADHD symptoms in parents, child's age, gender, IQ and birth weight. Our design is summarized in Fig. 1.

\section{Materials and methods}

\section{Participants}

The participating Dutch children with ADHD were part of a larger sample of the International Multi-Centre ADHD Gene (IMAGE) project. This is an international collaborative study that aims to identify genes that increase the 


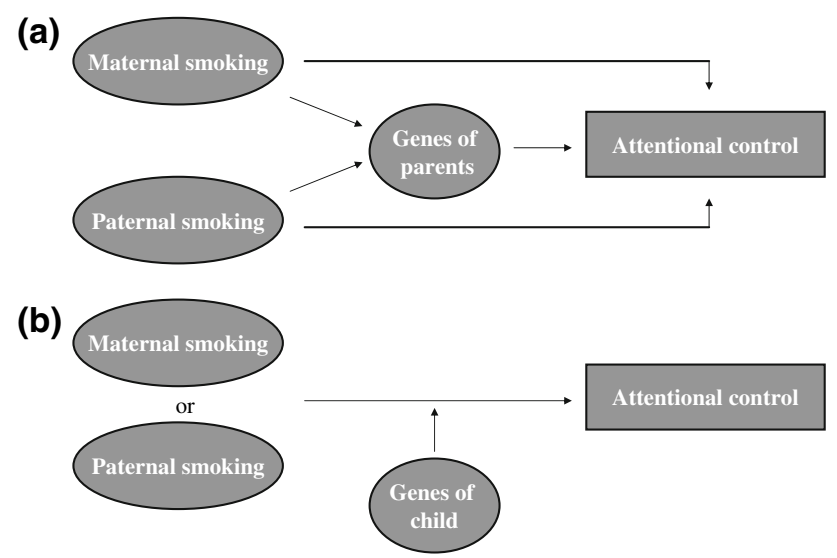

Fig. 1 Models of analyses. a Genetic mediation hypothesis, where smoking reflects a proxy risk for ADHD genes. b Gene by environment $(\mathrm{G} \times \mathrm{E})$ interaction

risk for ADHD using QTL linkage and association strategies [6]. The Dutch Image sites collected additional neuropsychological measures and information about prenatal risk factors. To participate in IMAGE, probands were required to have a clinical diagnosis of DSM-IV combined subtype of ADHD, have one or more full siblings and at least one biological parent available for clinical information and DNA collection. The control families were recruited from primary and high schools located in Nijmegen. Controls and their first-degree relatives were required to have no formal or suspected ADHD diagnosis.

Ethical approval was obtained from National Institutes of Health recognized local ethical review boards and all families gave written informed consent prior to participation. All children participating were aged 5-17 years and of European Caucasian descent. Exclusion criteria applying to all children included IQ $\leq 70$, or the presence of autism, epilepsy, general learning difficulties, brain disorders and any genetic or medical disorder associated with externalizing behaviors that might mimic ADHD.

Details of the sample collection for this study and screening procedures are described elsewhere [6]. In short, the ADHD children and their siblings were recruited from families referred to several participating (academic) child psychiatric and pediatric outpatient clinics, or from members of the Dutch Parents' ADHD Association. All probands were included after completing clinical evaluations by a pediatrician or child psychiatrist prior to the study. The children were screened with the following rating scales: parent and teacher Conners' long version rating scales, the strength and difficulties questionnaire (SDQ) [20]. Only clinical cases with an average $T$-score of the DSM-IV total symptom score $(N$-scale) greater than 63 on the Conners scales and scores $>90$ th percentile on the SDQ-hyperactivity scale were recruited for IMAGE.
Subsequently, the parental account of childhood symptoms (PACS) was administered to cases who scored clinically on any of the questionnaires [53]. A standardized algorithm for PACS was applied to all raw PACS data to yield diagnosis based on operational DSM-IV criteria for ADHD [6]. For the screening of the control children, parents and teachers completed the Conners rating scales. They were only included with a $T$-score of the $N$-scale lower than 63.

Pro-rated full intelligence quotient (IQ) scores were derived from four subtests of the Wechsler Intelligence Scale for Children (WISC-III NL) [56]: picture completion, block design, similarities and vocabulary [45].

Psychostimulants (e.g., methylphenidate 71\%) were required to be withdrawn for at least 2 days prior to neuropsychological assessment, since they may positively influence reaction time measures [14]. Withdrawal of other medication (present in $29 \%$ of children) was done in consultation with a senior psychiatrist.

In this study 56 ADHD families and 50 control families participated and had the attentional control variable available. The ADHD families consisted of 56 probands, their 23 affected siblings. Control families consisted of 105 children. See Table 1 for the demographics.

\section{Procedure}

The ADHD children were tested at Karakter University Centre for Child and Adolescent Psychiatry in Nijmegen. Testing required approximately $2-3 \mathrm{~h}$ and took place in a quiet test room by experienced child and adolescent psychologists and trained undergraduate students. Siblings of the same family were tested simultaneously. The control group was assessed at their school or at the center. The administration of neuropsychological tests was counterbalanced to rule out possible effects of fatigue on the tests.

Instruments and measures

Pregnancy, birth and child's first week's questionnaire

Parents were asked to complete the pregnancy, birth and child's first week's questionnaire, specifically designed for this study to obtain information concerning prenatal exposure to smoking and alcohol, pregnancy and obstetric variables such as birth weight. Mothers and fathers were asked to provide retrospective information on their use of tobacco before, during, and 1 year after the pregnancy for each child. They indicated the number of cigarettes per day on a six-point scale: 0 cigarettes, 1-5 cigarettes, 6-10 cigarettes, 11-15 cigarettes, 16-20 cigarettes, $>20$ cigarettes for each trimester. See Table 2 for the amount of cigarettes per group. The amount of cigarettes smoked by 
Table 1 Sample characteristics

\begin{tabular}{|c|c|c|c|c|c|c|c|}
\hline & \multicolumn{2}{|c|}{ ADHD } & \multicolumn{2}{|c|}{ ADHD } & \multicolumn{2}{|c|}{ Normal } & \multirow{3}{*}{ Statistics } \\
\hline & \multicolumn{2}{|c|}{ Probands $(N=56)$} & \multicolumn{2}{|c|}{ Affected siblings $(N=23)$} & \multicolumn{2}{|c|}{ Controls $(N=105)$} & \\
\hline & $M$ & SD & $M$ & SD & $M$ & SD & \\
\hline & & & & & & & $\chi^{2}$ \\
\hline Male $(\%)$ & 78.6 & & 47.8 & & 45.7 & & $\begin{array}{l}16.70 * \\
F_{1,184}\end{array}$ \\
\hline Age (years) & 12.5 & 2.4 & 12.1 & 2.5 & 12.5 & 2.6 & ns \\
\hline Estimated full scale IQ & 97.4 & 10.8 & 100.3 & 11.5 & 105.7 & 11.5 & $10.2 *$ \\
\hline ADHD diagnosis & & & & & & & \\
\hline Inattentive $(N)$ & - & & 2 & & - & & \\
\hline Hyperactive-impulsive $(N)$ & - & & - & & - & & \\
\hline Combined $(N)$ & 56 & & 21 & & - & & \\
\hline Anxiety disorder $(N)$ & 28 & & - & & - & & \\
\hline
\end{tabular}

$M$ mean; $S D$ standard deviation; $A D H D$ attention-deficit/hyperactivity disorder; $D S M$ - $I V$ Diagnostic and Statistical Manual for Mental Disorders (4th edition); $n s$ non-significant

* $P<0.05$; contrasts based on $P$-values of 0.05

Table 2 Prevalence of maternal and paternal smoking during pregnancy for ADHD children and controls

\begin{tabular}{llcccc}
\hline \multicolumn{5}{c}{ Prevalence smoking during pregnancy $N(\%)$} \\
\cline { 2 - 6 } & Exposed total & $1-5$ cigarettes & $6-10$ cigarettes & $11-15$ cigarettes & \\
\hline Maternal smoking & & & & \\
ADHD & $22(27.8)$ & $12(15.2)$ & $2(10.1)$ & $2(2.5)$ & 0 \\
Controls & $11(10.5)$ & $9(8.6)$ & & 0 & 0 \\
Paternal smoking & & $2(2.5)$ & $14(17.7)$ & $17(21.5)$ & $8(10.1)$ \\
ADHD & $41(51.9)$ & $14(13.3)$ & $11(10.5)$ & $9(8.6)$ & $6(5.7)$ \\
Controls & $40(38.1)$ &
\end{tabular}

both parents during pregnancy was very similar in each trimester. For example, $93 \%$ of the mothers who smoked during the first trimester continued to smoke in the second trimester and $91 \%$ in the third trimester. On the basis of the distribution and the consistency across trimesters, we derived one overall measure of smoking during pregnancy, and dichotomized this into 'yes' $(=1)$ and 'no' $(=0)$. Information on tobacco use during pregnancy was available in all cases. As the questionnaire used also contained information regarding maternal alcohol use during pregnancy, this was also evaluated. In $26.5 \%$ of the children, mothers used alcohol during pregnancy.

\section{Parental ADHD symptoms}

Information concerning parental ADHD DSM-IV symptoms was obtained with the Dutch self-report questionnaire [27]. Five complex items from the original 18 DSM-IV items [12] were reformulated, each into two statements. As a result, the rating scale consisted of 23 questions about behavior within the last 6 months and 23 questions about their childhood (1-12 years). Each item was rated on a four-point scale ( $0=$ 'rarely or never', $1=$ 'sometimes', $2=$ 'often', 3 = 'very often'). A symptom was considered to be present when it was rated as 'often' or 'very often'. The 23 items for each scale were recalculated into the original 18 DSM-IV items (9 for hyperactive symptoms, 9 for inattentive symptoms). The current symptoms for hyperactivity and inattentiveness were summarized for a total ADHD symptom score, which was used as an index of adult ADHD severity.

Outcome variable

Attentional control was measured by the sustained attention task of the Amsterdam Neuropsychological Tasks (ANT) [11]. In this visual continuous performance task, 50 series of 12 patterns (600 signals) in which an equal number of signals consisting of 3 (non-target), 4 (target) or 5 (non-target) dots are presented in random order. 
The child was required to press a "yes" key, when a target signal was displayed and a "no" key when the non-target was shown. Duration of the task was on average $15 \mathrm{~min}$ and the target rate was $33 \%$. Feedback with a sound was given for the errors the subjects made. The standard deviation of the completion times of 50 series represented attentional control [47, 51]. Internal consistency of the ANT is satisfactory to good [10].

\section{Genotypes (available for ADHD families only)}

We explored three polymorphisms found to be increasing the risk for ADHD in earlier studies [2, 18], namely the $D R D 4$ variable number of tandem repeat (VNTR) in exon 3 of the gene (risk factor for ADHD: 7-repeat allele carriership), the DAT1 $3^{\prime}$ UTR VNTR [risk factor for ADHD: homozygous genotype for 10-repeat allele (10/10)], and the VNTR in intron 8 of DAT1 [DAT1 INT8; defined risk factor for ADHD: homozygous genotype for the 6-repeat allele (6/6)]. Furthermore, we explored the effects of the homozygous DATl haplotype 10/6_10/6 also known to increase the risk for ADHD (defined risk: DATl haplotype 10/6_10/ 6 versus others) [2]. DNA collection and genotyping methodology has been described elsewhere [6]. In short, blood samples were sent to Rutgers University Cell and DNA Repository, NJ, USA, directly after collection. DNA was extracted there from part of the blood or from immortalized cell lines. DNA stocks were collated at the Social, Genetic and Developmental Psychiatry Center (SGDP) laboratories in London where they were stored, organized and plated out for further analysis. Geneservice Ltd., Cambridge (UK) performed whole genome amplification on all samples with $<100 \mu \mathrm{g}$ stock DNA, using the REPLI-g kit (Quiagen Ltd, Crawley, UK). A summary score (range 0-3) was also constructed for the DRD4 and $D A T 1$ genetic risk factors, as follows: for every genetic risk factor present, parents and children received the value of 1 , adding up to a maximum of 3 . Those who did not carry any of the risk factors were given the value of 0 .

\section{Statistical analyses}

All analyses were performed using the Statistical Package for the Social Sciences (SPSS for Windows, version 12.01.1). When missing data (concerning birth weight, prorated IQ, CTRS-R: L) were less than $5 \%$, they were imputed using the Estimation Maximization procedure [52]. $P$-values below 0.05 were regarded as significant.

Correlations, chi-square analyses, Mann-Whitney $U$ tests, analyses of variance (ANOVA) and Linear Mixed Models (LMM) were conducted for the descriptive variables and to test possible covariates. The selection of covariates was based on theoretical considerations (reported in literature) and empirical reasons (relationships within the data). The initial models were adjusted for age (years), gender (male/female), IQ, birth weight (grams), oppositional symptoms of the child ( $A$-scale Conners), anxious-shy symptoms ( $D$-scale Conners), total maternal or paternal ADHD symptoms, maternal age (years) and socio economic status. All covariates were run in the initial models, and when showing a significant association with attentional control, were kept in the LMMs. This was the case for age, gender and IQ.

Since the sample consisted partly of siblings, which included non-independent observations, LMMs were carried out to account for the within-family correlation [52]. In the LMMs ADHD status (yes/no) and maternal or paternal smoking during pregnancy (yes/no) were regarded as fixed factors and family as a random factor. Furthermore, interactions factors between ADHD status and parental smoking were constructed. Models were tested for maternal and paternal smoking separately.

To test for genetic mediation, LMM analyses were run with prenatal exposure to smoking as the main predictor and attentional control as the dependent variable in the ADHD families, only, since no genetic information was available for the control families. We then examined whether adding parental genotypes to the model would reduce the effect of prenatal smoking. To test for interactions effects between prenatal exposure to smoking and genotypes of the child, LMM analyses were run, separately for each genetic risk. Genetic risk and maternal/paternal smoking were regarded as fixed factors and family as a random factor.

Since the dependent variable showed a non-normal distribution, it was logtransformed before running the LMMs.

\section{Results}

Children exposed prenatally to smoking had a lower birth weight (mean difference $=214 \mathrm{~g}$ ), compared to those who were not exposed $[F(1,153.5)=4.0 ; P=0.047]$. According to the Mann Whitney $U$-test the self-reported total ADHD symptoms of both parents were significantly higher in the ADHD group compared to the control group (mother: $Z=-3.1, P=0.002$; father: $Z=-2.3, P=0.02$ ). Smoking and non-smoking parents did not differ in self-reported total ADHD symptoms (mother: $Z=-0.27, P=0.785$; father: $Z=-0.61, P=0.545)$.

During pregnancy $27.8 \%$ of the mothers in the ADHD group smoked compared to $10.5 \%$ of the mothers in the control group $\left[\chi^{2}(1,184)=9.24 ; P=0.002 ;\right.$ OR $=3.29$; 95\% CI 1.48-7.30]. Similarly, more fathers of children with ADHD smoked than fathers of control children during 
mother's pregnancy $\left[51.9 \%\right.$ vs. $38.1 \% ; \chi^{2}(1,184)=3.49$, $P=0.06 ;$ OR $=1.75 ; 95 \%$ CI $0.97-3.17]$. In a logistic regression analysis ADHD status was predicted by maternal smoking $(\mathrm{OR}=3.29$; CI 95\% 1.48-7.30; $P=0.003$ ). This relationship was partly mediated by the performance on attentional control (maternal smoking OR $=2.42$, CI 95\% 1.04-5.61, $P=0.039$; attentional control: $\mathrm{OR}=2.93$, CI $95 \% 1.78-4.84, P<0.001)$.

With regard to alcohol use $26.5 \%$ of the children were exposed to alcohol during pregnancy. The frequencies did not differ between the children affected with ADHD and the controls $\left[\chi^{2}(1,182)=0.585, P=0.44 ; \mathrm{OR}=0.77 \mathrm{CI}\right.$ 95\% 0.39-1.50].
Prenatal exposure to maternal and paternal smoking

In both LMM analyses, the child's ADHD status was a strong predictor of attentional control. The two groups differed both in means and standard deviations. In the model for maternal smoking, the effect of smoking reached significance at a trend level $[F(1,130.3)=3.33, P=0.07]$. Group comparison showed that children exposed to prenatal smoking performed worse compared to children who were not exposed. Maternal smoking did not interact with ADHD status, suggesting that this small effect was not different for the control or ADHD children (see Fig. 2). In the model of paternal smoking no main effect of paternal
Fig. 2 The effect of paternal and maternal smoking stratified by ADHD status. In $\mathbf{b}$ the interaction effect between paternal smoking and ADHD status is shown $(P=0.007)$. For maternal smoking (a) the effect of smoking is the same in the both groups. A higher score means a more variable performance

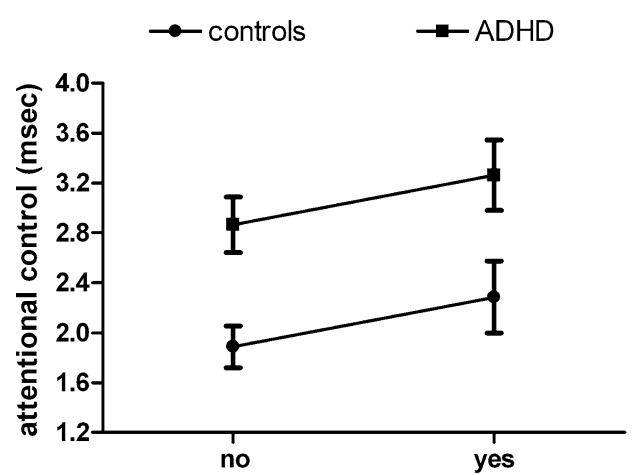

(a) maternal smoking

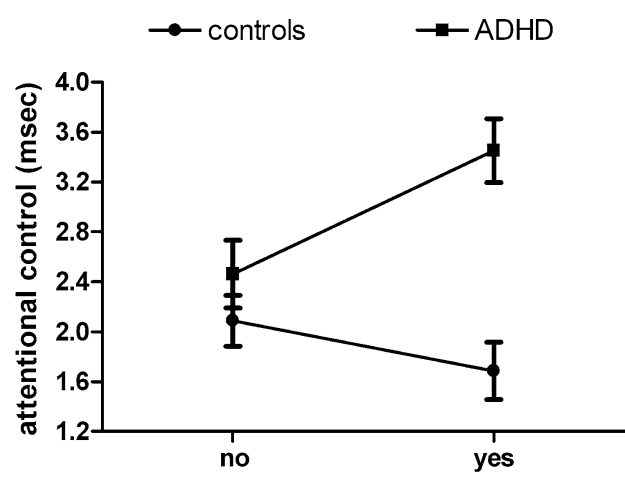

(b) paternal smoking

Table 3 Genetic frequencies of both parents stratified according to smoking behavior

\begin{tabular}{|c|c|c|c|c|c|c|}
\hline & \multicolumn{3}{|c|}{ Father \% $(N)$} & \multicolumn{3}{|c|}{ Mother \% $(N)$} \\
\hline & All & Non-smoking & Smoking & All & Non-smoking & Smoking \\
\hline \multicolumn{7}{|l|}{ DAT13UTR } \\
\hline $9 / 9$ or $9 / 10$ & $42.9(21)$ & $50(11)$ & $37(10)$ & $45.3(24)$ & $44.4(16)$ & $47.1(8)$ \\
\hline $10 / 10$ & $57.1(28)$ & $50(11)$ & $63(17)$ & $54.7(29)$ & $55.6(20)$ & $52.9(9)$ \\
\hline \multicolumn{7}{|l|}{ DAT1 INT8 } \\
\hline Other & $40.8(20)$ & $54.5(12)$ & $29.6(8)$ & $41.5(22)$ & $33.3(12)$ & $58.8(10)$ \\
\hline $6 / 6$ & $59.2(29)$ & $45.5(10)$ & 70.4 (19) & $58.5(31)$ & $66.7(24)$ & $41.2(7)$ \\
\hline \multicolumn{7}{|l|}{ DRD4 7-repeat } \\
\hline Non-carrier & $67.3(33)$ & $77.3(17)$ & $59.3(16)$ & $69.8(37)$ & $72.2(26)$ & $64.7(11)$ \\
\hline Carrier & 32.7 (16) & $22.7(5)$ & $40.7(11)$ & $30.2(16)$ & $27.8(10)$ & $35.3(6)$ \\
\hline \multicolumn{7}{|l|}{ DAT1 haplotype } \\
\hline Other & $53.1(26)$ & $59.1(13)$ & $48.1(13)$ & $54.7(29)$ & $50(18)$ & $64.7(11)$ \\
\hline $10 / 6 \_10 / 6$ & $46.9(23)$ & $40.9(9)$ & $51.9(14)$ & $45.3(24)$ & $50(18)$ & $35.3(6)$ \\
\hline \multicolumn{7}{|c|}{ DRD4, DAT1 10/10 and DAT1 6/6 } \\
\hline No risk alleles & $22.4(11)$ & $40.9(9)$ & $7.4(2)$ & $20.8(11)$ & $19.4(7)$ & $23.5(4)$ \\
\hline 1 risk allele & $20.4(10)$ & $13.6(3)$ & $25.9(7)$ & $32.1(17)$ & $27.8(10)$ & $41.2(7)$ \\
\hline 2 risk alleles & $42.9(21)$ & $31.8(7)$ & $51.9(14)$ & $30.2(16)$ & $36.1(13)$ & $17.6(3)$ \\
\hline \multirow[t]{2}{*}{3 risk alleles } & $14.3(7)$ & $13.6(3)$ & $14.8(4)$ & $17(9)$ & $16.7(6)$ & $17.6(3)$ \\
\hline & 49 & 22 & 27 & 53 & 36 & 17 \\
\hline
\end{tabular}

This table describes frequencies for ADHD families, only 
smoking was found $[F(1,86.6)=0.50, P=0.48]$, but the interaction between paternal smoking and ADHD status of the child was significant $[F(1,86.8)=7.62, P=0.007]$. This indicates that paternal smoking on its own was not associated with attentional control in all the offspring, but that it did have a negative effect on attentional control only in children with ADHD, as illustrated in Fig. 2. Attentional control was not affected by alcohol use of the mother during pregnancy $[F(1,122.52)=0.915, \quad P=0.341]$. Therefore, we did not investigate prenatal alcohol exposure further in this study.

Genetic mediation (ADHD families only)

To test our hypothesis that paternal smoking is a proxy for genetic risk factors for poor attentional control and ADHD, we explored the relationship between the number of genetic risk factors and smoking during pregnancy in those fathers and mothers who smoked. See Table 3 for genetic risk factor frequencies of the parents according to smoking behavior. The results show a significant relationship between the number of genetic risk factors of fathers and their smoking behavior (Table 4; Fig. 3). This relationship was not significant for mothers. The strongest effect is found when the risk factors DRD4 7-repeat allele and the DATI INT8 6/6 genotype are combined. No associations were found with the polymorphisms individually or with the homozygous risk DATl haplotype (Table 4). Smoking fathers compared to smoking mothers did not differ significantly in the number of genetic risk factors (see Table 4).

To further explore the genetic mediation hypothesis we directly analyzed whether paternal risk genes mediated the "paternal smoking effect". Adding the paternal genotypes to a model with attentional control as dependent variable,

Table 4 Results of associations between genetic risk factors and smoking during pregnancy of both parents (ADHD families)

\begin{tabular}{|c|c|c|c|c|c|c|c|c|c|c|c|c|}
\hline & \multicolumn{4}{|c|}{ Paternal smoking } & \multicolumn{4}{|c|}{ Maternal smoking } & \multicolumn{4}{|c|}{ Fathers versus mothers smoking* } \\
\hline & $\chi^{2}$ & $d f$ & $N$ & $P$ & $\chi^{2}$ & $d f$ & $N$ & $P$ & $\chi^{2}$ & $d f$ & $N$ & $P$ \\
\hline \multicolumn{13}{|l|}{ Genes } \\
\hline DRD4 7-repeat allele & 1.79 & 1 & 49 & 0.181 & 0.04 & 1 & 53 & 0.842 & 0.13 & 1 & 44 & 0.718 \\
\hline DAT1 $3^{\prime} \mathrm{UTR}$ & 3.12 & 1 & 49 & 0.078 & 3.09 & 1 & 53 & 0.079 & 0.43 & 1 & 44 & 0.510 \\
\hline DAT1 INT8 & 0.83 & 1 & 49 & 0.362 & 0.31 & 1 & 53 & 0.578 & 3.68 & 1 & 44 & 0.055 \\
\hline DAT1 haplotype & 0.58 & 1 & 49 & 0.445 & 1.01 & 1 & 53 & 0.315 & 1.15 & 1 & 44 & 0.283 \\
\hline \multicolumn{13}{|l|}{ Genetic risk factors } \\
\hline DRD4 7-repeat allele, DAT1 3'UTR 10/10, DAT1 INT8 6/6 & 8.10 & 3 & 49 & 0.044 & 1.66 & 3 & 53 & 0.645 & 5.96 & 3 & 44 & 0.113 \\
\hline DRD4 7-repeat allele, DAT1 3UTR 10/10 & 4.24 & 2 & 49 & 0.120 & 0.47 & 2 & 53 & 0.789 & 1.41 & 2 & 44 & 0.493 \\
\hline DRD4 7-repeat allele, DAT1 INT8 6/6 & 7.17 & 2 & 49 & 0.028 & 0.95 & 2 & 53 & 0.399 & 3.86 & 2 & 44 & 0.145 \\
\hline DRD4 7-repeat allele, DAT1 haplotype 10/6_10/6 & 4.39 & 2 & 49 & 0.111 & 0.43 & 2 & 53 & 0.809 & 3.6 & 2 & 44 & 0.165 \\
\hline
\end{tabular}

DRD4 dopamine receptor D4; DAT1 the dopamine transporter; $3^{\prime} U T R$ located in the $3^{\prime}$ untranslated region; INT8 intron 8

* Number of genetic risk factors in smoking fathers compared to smoking mothers

The $P$ value of the bold figures is $<0.05$

Fig. 3 Percentages of smoking and non-smoking fathers and mothers according to the number of genetic risk factors (range 0-3): DRD4 7R allele, DAT1 $3^{\prime}$ UTR 10/10 and DAT1 INT8 6/6
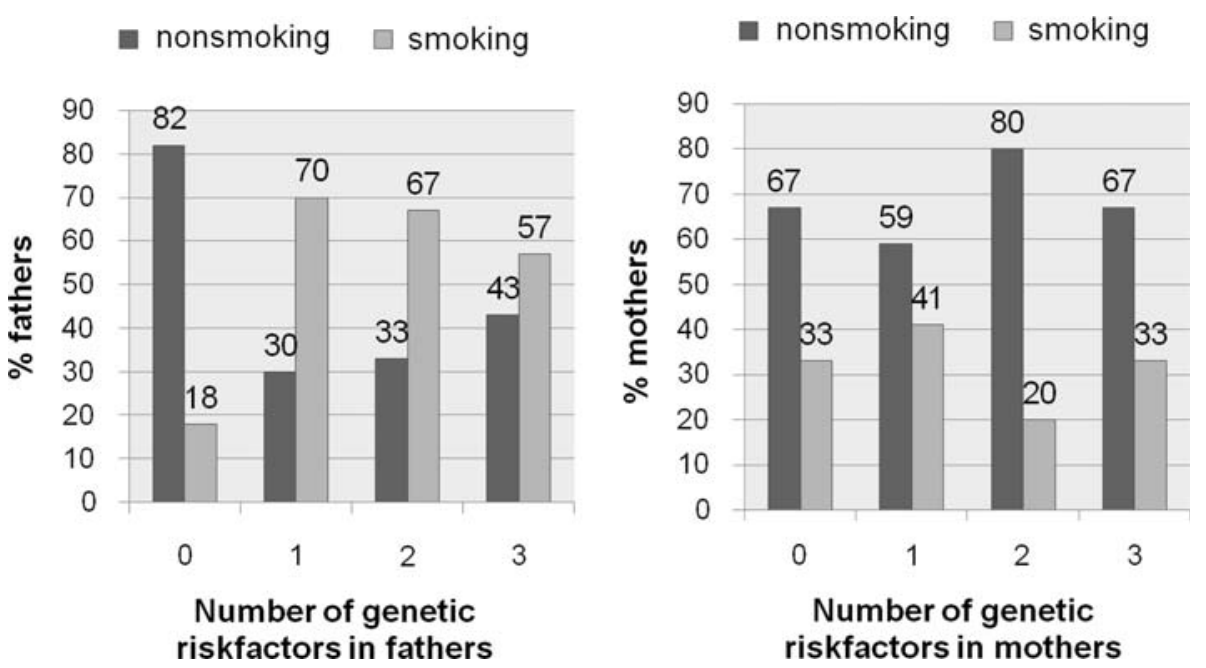
paternal smoking as predictor and age and gender as covariates reduced the significance of the effect of paternal smoking to non-significant. In the model with DRD4 7-repeat allele, DATI $3^{\prime}$ UTR 10/10, DAT1 INT8 6/6 this change was: $P=0.04$ versus $P=0.35$ ( $B$ change $=$ $-0.17)$. For the genetic risk DRD4 7-repeat allele, DAT1 $10 / 10$ the $P$-value changed to $P=0.37$ ( $B$ change $=$ $-0.17)$ as it also did for DRD4 7-repeat allele and DAT1 $6 / 6$ ( $B$ change $=-0.18)$. This indicates that the paternal risk genes mediate, at least partly, the paternal smoking effect on attentional control.

Interaction of prenatal exposure to smoking and genotypes of the child (ADHD families only)

To test whether the effect of prenatal exposure to smoking interacts with genetic risk factors in the child, we included the genotypes of the child and their interaction with smoking into the LMM models of maternal and paternal smoking on attentional control. We found no main effects of individual genes or a combination of genetic risks on attentional control. In addition we failed to find $\mathrm{G} \times \mathrm{E}$ effects (data not shown).

\section{Discussion}

This study is the first to examine the effect of prenatal exposure to smoking of both mothers and fathers on attentional control in children with and without ADHD, while controlling for possible covariates. Most but not all available studies indicate that prenatal exposure to cigarette smoke increases the risk for developing ADHD and negatively affects the cognitive functioning related to ADHD. As expected and reported earlier, ADHD status was a strong predictor of poor attentional control. Further, children with ADHD were significantly more likely to have been exposed to tobacco in utero. However, the effect of maternal smoking on attentional control in both ADHD children and controls was significant at trend level $(P=0.07)$. This result was unexpected, given previous population studies did find significant associations, albeit of small effect size, between maternal smoking and cognitive domains as learning, memory, problem-solving and eye-hand coordination [9]. This might be explained by the low percentage of mothers who smoked during pregnancy in our sample and the small number of cigarettes smoked per day (only $2.5 \%$ of the children, all in the ADHD group, were exposed to more than 10 cigarettes/day). A higher dosage is probably needed to cause an effect [46]. In fact, some of the harmful effects of smoking can be avoided, if mothers reduce smoking during pregnancy [43].
So far, studies have focused on maternal smoking. Since smoking behavior and ADHD are strongly associated [36], we examined the effect of both maternal and paternal smoking. Our most important finding was a strong effect of paternal smoking on attentional control but only in children with ADHD. Furthermore, we found a relationship between paternal smoking and the number of genetic risk factors in fathers, of which the combination of DRD4 7-repeat allele carriership and the 6/6 genotype of DATI INT8 showed the strongest effect. Furthermore, we found some evidence for genetic mediation, when fathers' genes were included in predicting the performance on attentional control. This finding validates our hypothesis of genetic mediation of the effect of paternal smoking, i.e., that the effect of paternal smoking is a proxy of the effect of common genetic risk factors for ADHD and/or smoking transmitted to the child. This is consistent with studies reporting specific genes to be associated with both ADHD and smoking addiction [29, 42]. That these underlying risk genes affect attentional control in children with ADHD and not in controls is most likely explained by their interaction with other genetic risk factors for ADHD, i.e., by gene-gene interactions. An example how a gene-gene interaction could negatively affect cognitive performance is shown by a recent report on a significant interaction between the DRD2 Taq1 and the DRD4 VNTR polymorphisms that reinforced impulsivity on a delay discounting task [13].

An explanation for the stronger effect of paternal smoking compared to maternal smoking is that much more fathers than mothers did smoke in the ADHD families $(51.9 \%$ vs. $27.8 \%)$, which in terms of statistical power may have hampered finding significant effects of maternal smoking on our dependent variable.

Another explanation for the much stronger effect of paternal smoking may be the presence of a parent of origin effect. Parents may differ in the amount and quality of risk factors transmitted to the child [21]. Several studies have found a consistent pattern of paternal transmission of ADHD associated genes compared to maternal transmission $[24,48]$. An Irish study reported larger odds ratio's when risk alleles of several candidate genes (DRD4, DRD5, $D A T 1, S E R T$ and TPH2) were transmitted through father compared to maternal transmission [22]. Heightened paternal transmission relative to maternal could be linked to genomic imprinting, defined as gene expression dependent on the parent of origin. There is some evidence to suggest it plays a role in the genetic etiology of ADHD [21] and it is thought to have an impact on brain development. It is, therefore, plausible that this epigenetic mechanism is involved in the pathogenesis of ADHD and attentional control [37].

Although there is emerging evidence that environmental factors may be particularly harmful in combination with 
susceptibility genes for the disorder, we were unable to document interaction effects between prenatal exposure to smoking and genotypes of the child on attentional control, which is probably because of limited statistical power.

Some researchers argue that retrospective prenatal assessment lacks validity. However, this has generally been proven to be good [44]. Furthermore, the overall rate of smoking during pregnancy in this study resembled the prevalence in previous studies in The Netherlands or elsewhere [46, 55]. We conducted conservative analyses by including a range of variables that are known to be linked with smoking (age, gender, IQ, birth weight, oppositional behavior, maternal age, SES and parental ADHD symptoms) and our associations remained. Other types of variables could account for the association between smoking and attentional control. These contextual factors, such as parenting, the presence of co-morbid disorders ODD and CD or other psychopathology in the parents and alcohol use during pregnancy warrant further investigation. Future studies should also explore parent of origin effects. More work is needed to examine if our results can be generalized to other cognitive domains.

Identification of both genetic and environmental mechanisms that affect cognitive deficits in ADHD can improve our understanding of the etiology of ADHD. A possible shared predisposition between ADHD and smoking provides more information about the underlying mechanisms, for example, the involvement of cholinergic and dopaminergic systems and gene-gene interactions, which can lead to new therapies for ADHD. With respect to prenatal care, it is important to emphasize the harmful effects of smoking during pregnancy. Prevention programs that take on this matter have shown to be useful [40].

Acknowledgments This study, part of the International Multicenter ADHD Genes Project (IMAGE), was partly funded by a grant assigned to Stephen Faraone by the National Institute of Mental Health (NIH grant \# R01 MH62873-01A1). We are grateful to all participating parents, children and teachers. Furthermore, we would like to thank A.B. Feuth for his statistical advice.

Open Access This article is distributed under the terms of the Creative Commons Attribution Noncommercial License which permits any noncommercial use, distribution, and reproduction in any medium, provided the original author(s) and source are credited.

\section{References}

1. American Psychiatric Association (1994) Diagnostic and statistical manual for mental disorders. American Psychiatric Press, Washington, DC

2. Asherson P, Brookes K, Franke B, Chen W, Gill M, Ebstein RP, Buitelaar J, Banaschewski T, Sonuga-Barke E, Eisenberg J, Manor I, Miranda A, Oades RD, Roeyers H, Rothenberger A, Sergeant J, Steinhausen HC, Faraone SV (2007) Confirmation that a specific haplotype of the dopamine transporter gene is associated with combined-type ADHD. Am J Psychiatry 164(4):674-677

3. Banerjee TD, Middleton F, Faraone SV (2007) Environmental risk factors for attention-deficit hyperactivity disorder. Acta Paediatr 96(9):1269-1274

4. Batstra L, Hadders-Algra M, Neeleman J (2003) Effect of antenatal exposure to maternal smoking on behavioural problems and academic achievement in childhood: prospective evidence from a Dutch birth cohort. Early Hum Dev 75(1-2):21-33

5. Batty GD, Der G, Deary IJ (2006) Effect of maternal smoking during pregnancy on offspring's cognitive ability: empirical evidence for complete confounding in the US national longitudinal survey of youth. Pediatrics 118(3):943-950

6. Brookes K, Xu X, Chen W, Zhou K, Neale B, Lowe N, Aneey R, Franke B, Gill M, Ebstein R, Buitelaar J, Sham P, Campbell D, Knight J, Andreou P, Altink M, Arnold R, Boer F, Buschgens C, Butler L, Christiansen H, Feldman L, Fleischman K, Fliers E, Howe-Forbes R, Goldfarb A, Heise A, Gabriels I, Korn-Lubetzki I, Marco R, Medad S, Minderaa R, Mulas F, Muller U, Mulligan A, Rabin K, Rommelse N, Sethna V, Sorohan J, Uebel H, Psychogiou L, Weeks A, Barrett R, Craig I, Banaschewski T, Sonuga-Barke E, Eisenberg J, Kuntsi J, Manor I, McGuffin P, Miranda A, Oades RD, Plomin R, Roeyers H, Rothenberger A, Sergeant J, Steinhausen HC, Taylor E, Thompson M, Faraone SV, Asherson P, Johansson L (2006) The analysis of 51 genes in DSM-IV combined type attention deficit hyperactivity disorder: association signals in DRD4, DAT1 and 16 other genes. Mol Psychiatry 11(10):934-953

7. Buitelaar JK (2005) ADHD: strategies to unravel its genetic architecture. J Neural Transm Suppl (69):1-17

8. Castellanos FX, Sonuga-Barke EJ, Scheres A, Di MA, Hyde C, Walters JR (2005) Varieties of attention-deficit/hyperactivity disorder-related intra-individual variability. Biol Psychiatry 57(11):1416-1423

9. Cornelius MD, Ryan CM, Day NL, Goldschmidt L, Willford JA (2001) Prenatal tobacco effects on neuropsychological outcomes among preadolescents. J Dev Behav Pediatr 22(4):217-225

10. De Sonneville LMJ (2005) Amsterdamse Neuropsychologische Taken: Wetenschappelijke en klinische toepassingen. Tijdschrift voor Neuropsychologie 027-41

11. De Sonneville LMJ (1999) Amsterdam Neuropsychological Task: a computer-aided assessment program. In: Den Brinker BPLM, Beek PJ, Brand N, Maarse SJ, Mulder LJM (eds) Cognitive ergonomics, clinical assessment and computer-assisted learning: computers in psychology. Swets \& Zeitlinger, Lisse, The Netherlands, pp 204-217

12. DuPaul GJ, Power TJ, Anastopoulos AD, Reid R (1998) ADHD rating scale-IV: checklists, norms and clinical interpretation. The Guilford Press, New York

13. Eisenberg DT, Mackillop J, Modi M, Beauchemin J, Dang D, Lisman SA, Lum JK, Wilson DS (2007) Examining impulsivity as an endophenotype using a behavioral approach: a DRD2 TaqI A and DRD4 48-bp VNTR association study. Behav Brain Funct 32

14. Epstein JN, Conners CK, Hervey AS, Tonev ST, Arnold LE, Abikoff HB, Elliott G, Greenhill LL, Hechtman L, Hoagwood K, Hinshaw SP, Hoza B, Jensen PS, March JS, Newcorn JH, Pelham WE, Severe JB, Swanson JM, Wells K, Vitiello B, Wigal T (2006) Assessing medication effects in the MTA study using neuropsychological outcomes. J Child Psychol Psychiatry 47(5): 446-456

15. Ernst M, Moolchan ET, Robinson ML (2001) Behavioral and neural consequences of prenatal exposure to nicotine. J Am Acad Child Adolesc Psychiatry 40(6):630-641

16. Eskenazi B, Castorina R (1999) Association of prenatal maternal or postnatal child environmental tobacco smoke exposure and 
neurodevelopmental and behavioral problems in children. Environ Health Perspect 107(12):991-1000

17. Faraone SV, Khan SA (2006) Candidate gene studies of attentiondeficit/hyperactivity disorder. J Clin Psychiatry 67(Suppl): 813-820

18. Faraone SV, Perlis RH, Doyle AE, Smoller JW, Goralnick JJ, Holmgren MA, Sklar P (2005) Molecular genetics of attentiondeficit/hyperactivity disorder. Biol Psychiatry 57(11):1313-1323

19. Geurts HM, van der Oord S, Crone EA (2006) Hot and cool aspects of cognitive control in children with ADHD: decisionmaking and inhibition. J Abnorm Child Psychol 34(6):813-824

20. Goodman R (2001) Psychometric properties of the strengths and difficulties questionnaire. J Am Acad Child Adolesc Psychiatry 40(11):1337-1345

21. Goos LM, Ezzatian P, Schachar R (2007) Parent-of-origin effects in attention-deficit hyperactivity disorder. Psychiatry Res 149 (1-3):1-9

22. Hawi Z, Segurado R, Conroy J, Sheehan K, Lowe N, Kirley A, Shields D, Fitzgerald M, Gallagher L, Gill M (2005) Preferential transmission of paternal alleles at risk genes in attention-deficit/ hyperactivity disorder. Am J Hum Genet 77(6):958-965

23. Julvez J, Ribas-Fito N, Torrent M, Forns M, Garcia-Esteban R, Sunyer J (2007) Maternal smoking habits and cognitive development of children at age 4 years in a population-based birth cohort. Int J Epidemiol 36(4):825-832

24. Kent L, Green E, Hawi Z, Kirley A, Dudbridge F, Lowe N, Raybould R, Langley K, Bray N, Fitzgerald M, Owen MJ, O'Donovan MC, Gill M, Thapar A, Craddock N (2005) Association of the paternally transmitted copy of common Valine allele of the Val66Met polymorphism of the brain-derived neurotrophic factor (BDNF) gene with susceptibility to ADHD. Mol Psychiatry 10(10):939-943

25. Knopik VS, Heath AC, Jacob T, Slutske WS, Bucholz KK, Madden PA, Waldron M, Martin NG (2006) Maternal alcohol use disorder and offspring ADHD: disentangling genetic and environmental effects using a children-of-twins design. Psychol Med 36(10):1461-1471

26. Kollins SH, McClernon FJ, Fuemmeler BF (2005) Association between smoking and attention-deficit/hyperactivity disorder symptoms in a population-based sample of young adults. Arch Gen Psychiatry 62(10):1142-1147

27. Kooij JJ, Buitelaar JK, van den Oord EJ, Furer JW, Rijnders CA, Hodiamont PP (2005) Internal and external validity of attentiondeficit hyperactivity disorder in a population-based sample of adults. Psychol Med 35(6):817-827

28. Langley K, Rice F, van den Bree MB, Thapar A (2005) Maternal smoking during pregnancy as an environmental risk factor for attention deficit hyperactivity disorder behaviour. A review. Minerva Pediatr 57(6):359-371

29. Laucht M, Becker K, El-Faddagh M, Hohm E, Schmidt MH (2005) Association of the DRD4 exon III polymorphism with smoking in fifteen-year-olds: a mediating role for novelty seeking? J Am Acad Child Adolesc Psychiatry 44(5):477-484

30. Leech SL, Richardson GA, Goldschmidt L, Day NL (1999) Prenatal substance exposure: effects on attention and impulsivity of 6-year-olds. Neurotoxicol Teratol 21(2):109-118

31. Li D, Sham PC, Owen MJ, He L (2006) Meta-analysis shows significant association between dopamine system genes and attention deficit hyperactivity disorder (ADHD). Hum Mol Genet 15(14):2276-2284

32. Linnet KM, Dalsgaard S, Obel C, Wisborg K, Henriksen TB, Rodriguez A, Kotimaa A, Moilanen I, Thomsen PH, Olsen J, Jarvelin MR (2003) Maternal lifestyle factors in pregnancy risk of attention deficit hyperactivity disorder and associated behaviors: review of the current evidence. Am J Psychiatry 160(6):10281040
33. Martin RP, Dombrowski SC, Mullis C, Wisenbaker J, Huttunen MO (2006) Smoking during pregnancy: association with childhood temperament, behavior, and academic performance. J Pediatr Psychol 31(5):490-500

34. Maughan B, Taylor A, Caspi A, Moffitt TE (2004) Prenatal smoking and early childhood conduct problems: testing genetic and environmental explanations of the association. Arch Gen Psychiatry 61(8):836-843

35. Milberger S, Biederman J, Faraone SV, Chen L, Jones J (1996) Is maternal smoking during pregnancy a risk factor for attention deficit hyperactivity disorder in children? Am J Psychiatry 153(9):1138-1142

36. Milberger S, Biederman J, Faraone SV, Jones J (1998) Further evidence of an association between maternal smoking during pregnancy and attention deficit hyperactivity disorder: findings from a high-risk sample of siblings. J Clin Child Psychol 27(3):352-358

37. Mill J, Petronis A (2008) Pre- and peri-natal environmental risks for attention-deficit hyperactivity disorder (ADHD): the potential role of epigenetic processes in mediating susceptibility. J Child Psychol Psychiatry

38. Neuman RJ, Lobos E, Reich W, Henderson CA, Sun LW, Todd RD (2007) Prenatal smoking exposure and dopaminergic genotypes interact to cause a severe ADHD subtype. Biol Psychiatry 61(12):1320-1328

39. Olds D (1997) Tobacco exposure and impaired development: a review of the evidence. Ment Retard Dev Disabil Res Rev 3:257-269

40. Olds DL, Henderson CR Jr, Tatelbaum R (1994) Prevention of intellectual impairment in children of women who smoke cigarettes during pregnancy. Pediatrics 93(2):228-233

41. Polanczyk G, de Lima MS, Horta BL, Biederman J, Rohde LA (2007) The worldwide prevalence of ADHD: a systematic review and metaregression analysis. Am J Psychiatry 164(6):942-948

42. Potter AS, Newhouse PA, Bucci DJ (2006) Central nicotinic cholinergic systems: a role in the cognitive dysfunction in attention-deficit/hyperactivity disorder? Behav Brain Res 175(2): 201-211

43. Raatikainen K, Huurinainen P, Heinonen S (2007) Smoking in early gestation or through pregnancy: a decision crucial to pregnancy outcome. Prev Med 44(1):59-63

44. Rice F, Lewis A, Harold G, van den BM, Boivin J, Hay DF, Owen MJ, Thapar A (2007) Agreement between maternal report and antenatal records for a range of pre and peri-natal factors: the influence of maternal and child characteristics. Early Hum Dev 83(8):497-504

45. Sattler JM (2001) Assessment of children: cognitive applications. Jerome M. Sattler Publisher, San Diego

46. Schmitz M, Denardin D, Laufer ST, Pianca T, Hutz MH, Faraone S, Rohde LA (2006) Smoking during pregnancy and attentiondeficit/hyperactivity disorder, predominantly inattentive type: a case-control study. J Am Acad Child Adolesc Psychiatry 45(11): $1338-1345$

47. Slaats-Willemse D, Swaab-Barneveld H, De SL, Buitelaar J (2005) Familial clustering of executive functioning in affected sibling pair families with ADHD. J Am Acad Child Adolesc Psychiatry 44(4):385-391

48. Smoller JW, Biederman J, Arbeitman L, Doyle AE, Fagerness J, Perlis RH, Sklar P, Faraone SV (2006) Association between the 5HT1B receptor gene (HTR1B) and the inattentive subtype of ADHD. Biol Psychiatry 59(5):460-467

49. Sonuga-Barke EJ (2005) Causal models of attention-deficit/ hyperactivity disorder: from common simple deficits to multiple developmental pathways. Biol Psychiatry 57(11):1231-1238

50. Stins JF, Tollenaar MS, Slaats-Willemse DI, Buitelaar JK, Swaab-Barneveld H, Verhulst FC, Polderman TC, Boomsma DI 
(2005) Sustained attention and executive functioning performance in attention-deficit/hyperactivity disorder. Neuropsychol Dev Cogn C Child Neuropsychol 11(3):285-294

51. Swaab-Barneveld H, de Sonneville L, Cohen-Kettenis P, Gielen A, Buitelaar J, Van Engeland H (2000) Visual sustained attention in a child psychiatric population. J Am Acad Child Adolesc Psychiatry 39(5):651-659

52. Tabachnick BG, Fidell LS (2007) Using multivariate statistics. Pearson Education, Inc., Boston

53. Taylor E, Schachar R, Thorley G, Wieselberg M (1986) Conduct disorder and hyperactivity: I. Separation of hyperactivity and antisocial conduct in British child psychiatric patients. $\mathrm{Br} \mathrm{J}$ Psychiatry 149760-767
54. Thapar A, Fowler T, Rice F, Scourfield J, van den BM, Thomas H, Harold G, Hay D (2003) Maternal smoking during pregnancy and attention deficit hyperactivity disorder symptoms in offspring. Am J Psychiatry 160(11):1985-1989

55. Vuijk P, van Lier PA, Huizink AC, Verhulst FC, Crijnen AA (2006) Prenatal smoking predicts non-responsiveness to an intervention targeting attention-deficit/hyperactivity symptoms in elementary schoolchildren. J Child Psychol Psychiatry 47(9): 891-901

56. Wechsler D (2002) Wechsler intelligence scale for children Derde Editie NL. Handleiding. The Psychological Corporation, London 